\title{
¿Cuál revisión del modernismo?
}

\author{
What Revision of Modernism?
}

Qual revisão do modernismo?

\section{Eneida Maria de Souza}

UNIVERSIDADE FEDERAL DE MINAS GERAIS (UFMG), BRASIL

Profesora titular en teoría literaria de la UFMG. Doctora en Literatura

Comparada y Semiología por la Université de Paris VII. Últimos títulos publicados: Critica cult (EDUFMG, 2002-2007), Pedro

Nava. O risco da memória (Funalfa, 2004), Tempo de pós-critica

(NAPq; FALE; UFMG, 1994), O século de Borges (Autêntica, 1999),

fanelas indiscretas. Ensaios de crítica biográfica (EDUFMG,

2011). Correo electrónico: eneidamariasouza@gmail.com

\author{
Artículo de reflexión \\ Artículo traducido por Maria Cândida Ferreira de Almeida y Juan David Pedraza \\ (graduado en Literatura de la Universidad de los Andes, Bogotá). \\ Documento accesible en línea desde la siguiente dirección: http://revistas.javeriana.edu.co \\ doi:10.11144/Javeriana.CL18-35.crdm
}




\section{Resumen}

El artículo hace una

reformulación de los conceptos

de modernidad y de lo moderno

en relación con los movimientos

artísticos brasileños de la

década de 1920. Las obras de

los principales exponentes del

modernismo brasileño, Oswald

de Andrade y Mario de Andrade,

se ponen en diálogo con la

teoría de la deconstrucción

para mostrar cómo estos dos

escritores prefiguraban en su

época lo dicho más tarde por los

teóricos de esta línea. Además

de referirse a las múltiples caras

de lo moderno en Brasil a través

del cambio arquitectónico en

Belo Horizonte, se señalan

las perspectivas sobre la

modernización nacional que se

dan en la obra de autores de esa

región. Finalmente, el texto se

centra en la lectura pionera de

Silviano Santiago, para revisar

las fronteras que enmarcan los

términos moderno y modernista,

y en especial en la revaluación de

la figura canónica de Mário de

Andrade.

Palabras clave: modernidad, deconstrucción, Silviano

Santiago.

Palabras descriptor: Ciencia política - América Latina, internacionales comunistas, izquierdas (Política), estudios culturales.

\section{Abstract}

The article makes a reformulation of the concepts

of modernity and modern in relation to Brazilian art movements 1920s. The works of the leading exponents of Brazilian modernism, Oswald de Andrade and Mario de Andrade are put into dialogue with the theory of deconstruction to show how these two writers at the time foreshadowed what was said later by theorists of this line. In addition to showing the many faces of the modern in Brazil through the architectural change in Belo Horizonte, outlines the prospects for national modernization occurring in the work of authors from that region. Finally, put on reading lights pioneer Silviano Santiago in the revision of the borders that frame the terms modern, modernist, especially in the revaluation of the canonical figure of Mário de Andrade.

Keywords: Modernity, deconstruction, Silviano Santiago.

Keywords plus: Political Science - Latin America, Communist International, Left (Politics), cultural studies.

\section{Resumo}

O artigo faz uma reformulação dos conceitos de modernidade e de modernos em sua relação com os movimentos artísticos brasileiros da década de 20 do século XX. As obras dos principais expoentes do modernismo brasileiro, Oswald de Andrade e Mário de Andrade se coloca em diálogo com a teoria da desconstrução a fim de mostrar como estes dois escritores prefiguram na sua época o que foi desenvolvido mais tarde pelos teóricos da desconstrução. Além de mostrar as múltiplas caras do moderno no Brasil, a través da mudança arquitetônica em Belo Horizonte, se apontam as perspectivas sobre a modernização nacional que de dará na obra dos autores desta região. Enfim, se enfoca a leitura pioneira de Silviano Santiago na revisão das fronteiras que dividem os temos moderno, modernisya e em especial na figura canônica de Mário de Andrade.

Palavras-chave: modernidade, desconstrução, Silviano Santiago.

Palavras-chave descritores:

Ciência Política - América

Latina, Internacional Comunista, Esquerda (Politics), os estudos culturais.

RECIBIDO: 4 DE MARZO DE 2013. EVALUADO: 17 DE ABRIL DE 2013. ACEPTADO: 19 DE ABRIL DE 2013.

Cómo citar este artículo:

de Souza, Eneida Maria. “¿Cuál revisión del modernismo?”.

Cuadernos de Literatura 18. 35 (2014): 51-72. 


\section{Las varias caras de lo moderno}

La revisión del modernismo de 1922 se viene realizando desde hace mucho tiempo. Durante las conmemoraciones de sus noventa años, otras lecturas concurren para ampliar y revigorizar el legado del movimiento, y se incluye allí lo que se entiende por sus residuos y sus vacíos. Mário de Andrade, uno de los más significativos representantes de esa escuela, ya había apuntado, en 1942, los pros y los contras de esta corriente artística y literaria inaugurada a principios del siglo XX. La crítica al modernismo ya se estaba haciendo desde los años treinta, referencia encontrada en el artículo de Silviano Santiago, "Fechado para balanço" ("Cerrado por inventario"), en el cual afirma que la contestación tenía por base Río de Janeiro y el movimiento literario que allá se desarrollaba. Una nueva época se desplegaba para los colaboradores de la revista Lanterna Verde, entre quienes se destacaban Tristão de Ataíde, Octávio de Faria y Jorge Amado. Partidarios de ideologías diferentes, estos intelectuales se unieron en contra del liberalismo clásico y el nihilismo de 1922, en defensa de un periodo de esperanzas para la cultura, y constituyeron así una fuerza política que reunía catolicismo con integralismo ${ }^{1}$ y comunismo con estalinismo ${ }^{2}$. Con ocasión de la aparición de la novela regionalista y realista de 1930, Graciliano Ramos fue uno de los más fieles detractores del modernismo, por su defensa del lenguaje culto en detrimento de las conquistas de este movimiento en cuanto a la oralidad y a la aceptación del lenguaje popular y "brasilero". Estas diferencias de estilo y de propuestas estéticas provocaron, incluso, equívocos y preconceptos en relación con el éxito del movimiento, al recibir el apoyo de profesores universitarios y de miembros de academias literarias de la época, posición que se extiende hasta nuestros días. La turbulenta situación política del país en el periodo contribuía a que la prosa modernista fuera asociada a la falta de rigor del lenguaje y a la necesidad de cambios sociales, que quedaban restringidos, según Ramos, al ámbito de la ruptura gramatical y lingüística. La reacción de los escritores considerados posmodernistas serviría de mote para el juzgamiento del movimiento paulista como desprovisto de seriedad. Sin embargo, la revolución cultural estaba consolidada en todos los ámbitos de la vida y del arte. En entrevista concedida a Homero Senna, en 1948, así se expresó el escritor:

1 Corriente fascista brasileña.

2 " [...] o modernismo de 22 é enterrado em 1936 ao repicar dos sinos maniqueus (nitidez na oposição de luz e sombra, de Deus e o Diabo, de catolicismo e comunismo). As vozes dos sinos guerreiros traçam o perfil do intelectual intolerante, de feição totalitária e bem pouco democrático nas suas intenções revolucionárias, pois deseja modernizar o Brasil e atualizar a sua arte pela destruição do seu oposto" (Santiago, "Fechado para balanço" 78). 
¿Y qué impresión le quedó del modernismo?

- Muy mala. Siempre pensé que aquello era un engaño deshonesto. Salvo rarísimas excepciones, los modernistas brasileños eran unos presumidos.

[...]. Los modernistas brasileños, confundiendo el ambiente literario del país con la academia, trazaron líneas divisorias, rígidas (pero arbitrarias) entre lo bueno y lo malo. Y, queriendo destruir todo lo anterior a ellos, condenaron, por ignorancia su desfachatez, muchas cosas que merecían ser salvadas.

- ¿Quiere decir que no se considera modernista?

- ¡Qué idea! Mientras los muchachos del 22 promovían su movimientico, yo me encontraba en Palmeira dos indios, en pleno sertón alagoano, que vendían tela en el balcón. (Senna 201)

Con motivo de la publicación de los reportajes relativos a los noventa años del movimiento, se constató la parcialidad en los temas tratados, semejante a la disputa ancestral entre el eje Río-São Paulo: no se hacía ninguna mención a los demás lugares donde ocurrieron manifestaciones que podrían acercarse a la revolución modernista. Artículos publicados en los periódicos Folha de S. Paulo, en O Estado de S. Paulo y en el Globo (Río de Janeiro) revelaron tanto la presencia del discurso resentido por parte del Globo -porque la Semana de Arte Moderno de 1922 no respetaba las que ya eran marcas de una modernidad naciente-como el discurso centralizador de la prensa paulista. En Minas, en el periódico Estado de Minas, se verificó la lógica posición de excluidos, al considerar la participación, aunque tardía, de los escritores de Minas Gerais, cuya voz estuvo ausente en 1922.

Con la publicación de las Memórias de Pedro Nava, principalmente Beiramar, en 1978, aumentó el nivel de comprensión del modernismo en Minas con el relato de uno de sus colaboradores, y con el trabajo de investigación en archivos personales y públicos, además de la contribución de los otros miembros del movimiento literario y político de Minas Gerais. La construcción de la ciudad de Belo Horizonte constituiría también la instauración de un marco del espacio moderno, por más que estuviera sujeta a las contradicciones de una sociedad conservadora y pautada por costumbres provincianas. El cambio de la capital de la ciudad de Ouro Preto a Belo Horizonte -del ambiente del interior al trazado geométrico y moderno- motivó la formación de un tipo de modernidad que se distanciaba de las otras. Entre lo arcaico y lo nuevo, el imperio y la república, se instauraba la constatación de que lo moderno estaba dotado de una naturaleza heterogénea y plural.

El desarrollo de algunos puntos con respecto a mi pesquisa del modernismo en los últimos treinta años no tendrá como enfoque prioritario el olvido 
o el enmascaramiento de las manifestaciones que se dieron en otros estados, con ocasión de las revisiones hechas a lo largo de estos noventa años. Lo que se propone en la actual visión crítica de la literatura y de los movimientos culturales es la tentativa de rescate de textos pertenecientes a las minorías, a los actos de naturaleza local, a la recuperación de acontecimientos omitidos por la historiografía oficial. Tal posición señala la desconfianza de orden metodológico de una aproximación relativa a la totalidad y a la omnisciencia de los resultados y de los procesos de restauración histórica. La predilección por esa metodología estriba en el ejercicio de la práctica de la fragmentación y del residuo, dado que las soluciones totalizantes están desacreditadas y son inoperantes a la hora de leer el pasado desde el punto de vista del presente. Ante esta configuración analítica, orientada por el recurso al fragmento y a la incompletitud, se aspira a dimensionar el nivel actual de información y de referencias, en un modo imparcial y relativo. No obstante, esta posición estratégica no ignora las relaciones entre lo particular y lo general, o en la terminología más reciente, entre lo local y lo global, en la medida en que no se concibe el fragmento sin la visión de que la totalidad permanece como espectro y deseo. Privilegiar el fragmento sobre el conjunto y viceversa consistiría en olvidar el pensamiento relacional y articulador de diferencias, así como que la visión del todo no es prioritaria en relación con el fragmento o con sus partes.

Lo que se requiere en este proceso de relectura del modernismo no es reivindicar la integración de figuras o autores excluidos del movimiento por motivo de la constitución del canon oficial. Sería pertinente analizar las razones de las omisiones, de las exclusiones, sin enfatizar la idea de que los excluidos pudieron haber sido precursores o pudieron haberse integrado al cuadro canónico del modernismo. Esta reivindicación, en lugar de ser combativa, comete el mismo error clasificatorio, al reconocer la importancia del movimiento en la entrada canónica (y retrasada) de los excluidos. Tras la canonización del modernismo se pretende proceder a su descanonización. Esta lectura tiende a desvincular el modernismo de su aspecto clasificatorio y excluyente, entendiendo que la exclusión también es parte del proceso. Se debe evitar, por tanto, el principio teleológico que preside la cronología de los movimientos y las prácticas positivistas de enmarcar y sistematizar las ideas en casilleros prefabricados. Para ello es imprescindible la contribución de Carlos Eduardo Capela, autor de fuó Bananére, irrisor, irrisorio, de 2009, cuando discurre sobre el papel del personaje inventado por el escritor paulista Alexandre Marcondes Machado a principios del siglo XX. Según la crítica -y, en este caso, la de Otto Maria Carpeaux- la tendencia analítica siempre se orientó a llevar adelante 
[...] la discusión sobre el posible papel del personaje en cuanto precursor del modernismo literario brasileño. Esa insistencia hace evidente el proceso de constitución e imposición del modernismo como una especie de marco o paradigma obligatorio, que provee un conjunto de predicados y puntos de vista con los cuales la dinámica cultural y literaria, sobre todo la de la primera mitad del siglo XX, es aprehendida. (Capela 62)

La conclusión a la que llegó Capela se basa en el argumento que redefine el concepto de modernidad, travestida en modernismo, a través de Jacques Rancière, para quien esta está regida por principios de unidad y exclusividad, una idea que categóricamente tenía un sentido único, "cuando la temporalidad propia al régimen estético de las artes es la de una copresencia de temporalidades heterogéneas" (Rancière, cit. en Capela 62). Ese modelo, ya deconstruido por Nietzsche y Foucault, entre otros, desconoce el desenvolvimiento armónico del acontecimiento, al entender que la historia se realiza por desplazamientos, rupturas y discontinuidades. Poner en duda las posibilidades de totalización de la historia corresponde a poner entre paréntesis la búsqueda de la verdad única por medio del sentido de origen y de fundamento.

El estilo popular del autor y la fusión cómica entre el habla italianizada y el portugués de los inmigrantes paulistas permitieron considerar al creador de La divina increnca (1915) como premodernista y preantropofágico. Lo situaron igualmente como precursor de escritos de Antônio de Alcântara Machado (Brás, Bexiga e Barra Funda [1927]) y de Oswald y Mário de Andrade. Pero lo que importa en esa reflexión de Capela es la deconstrucción de una historiografía cuyo modelo teleológico exhibe criterios de ruptura y evolución en las artes y en la cultura. Esa posición hace posible revertir lo que fue registrado como modernista, homologado por los manuales escolares, por la historiografía oficial y por los innúmeros estudios académicos centrados en la consolidación de determinados nombres y corrientes estéticas.

Como consecuencia de este debate, el concepto de lo moderno continúa aún sujeto a interpretaciones, revisiones y equívocos. En el acto festivo de las conmemoraciones, es común la realización de balances que resaltan el valor del movimiento y sus cualidades, en lugar de rever las faltas y vacíos del proyecto. Lo que importa es la constante relectura que se hace del modernismo y de sus representantes, lo que posibilita la actualización de los textos, la reconfiguración de posiciones asumidas o la transparencia de imágenes hasta entonces oscuras.

El modelo occidental y eurocéntrico de las teorías sobre la modernidad fue, por mucho tiempo, aceptado como único, sin que su hegemonía fuera contestada. 
Diferentes experiencias de la modernidad pueden ser observadas, considerando no solo la irregularidad temporal de su actualización por distintas culturas, sino también las singularidades múltiples y divergentes de esta vivencia dentro de las propias manifestaciones locales.

Uno de los parámetros de la crítica posmoderna consiste en la reescritura de la modernidad, para usar una expresión de J. F. Lyotard, procedimiento a través del cual se elabora un olvido inicial y se detecta lo que fuera reprimido. Según el filósofo, el prefijo pos, de posmoderno, no significa un movimiento de comeback, de repetición, sino un proceso de ana, un proceso de análisis, de anamnesis y de anamorfosis. Se constituye en una forma de reelaborar la modernidad, sustituyendo la idea de un retorno al comienzo por el movimiento de inscripción sobre sí misma, en los moldes de una escritura infinita. Las limitaciones propias de todo saber pasan a ser consideradas en su aspecto positivo, de modo que inciten a la reflexión sobre momentos de la historia que se presentan en su dimensión inacabada e inconclusa. Lejos de constituirse como trazo que contorna el dibujo complejo de la modernidad, la lectura posmoderna actúa como pliegue del discurso de la modernidad sobre sí mismo, como espejo invertido que refleja las distorsiones y el silencio de los discursos en juego.

Pensadores y teóricos contemporáneos han apuntado algunas posibles soluciones para salir de o entrar en la modernidad. Dotados de un pensamiento nómada y una experiencia vital en permanente desplazamiento, los autores se apropiarían de la teorización producida por los discursos hegemónicos para deconstruirlos. Romper estratégicamente con las teorías que consolidaron el mito de la modernidad se justifica por la urgencia de asumir nuevas propuestas capaces de contribuir al direccionamiento de las indagaciones del presente. Es por demás consensual la afirmación de que en el propio continente latinoamericano los hechos culturales y artísticos no se realizan de modo homogéneo. Jesús Martín-Barbero introdujo una reflexión original en los estudios de los medios -la modernidad descentrada- que responde a las varias temporalidades detectadas en la recepción de culturas hegemónicas por las periféricas. El modo por el cual la modernidad es referida es siempre plural, en virtud de la existencia de una distinta configuración conceptual, en la que el principio de homogeneidad es sustituido por el de heterogeneidad.

Se trata de alternativas de definición concernientes al término posmoderno. Cuando se propone reflexionar sobre los múltiples y complejos ámbitos de la cultura en América Latina, la noción de retraso, por ejemplo, se desvincula del contenido negativo y se impone como parte integrante del desfase temporal, del retraso, poniendo una señal de más de las regiones periféricas. La 
experiencia simultánea del tiempo impide concebir la realidad de los países periféricos de forma similar a la de los demás, pues es importante descartar argumentos de orden causal y progresista. Frente al término posmodernidad, de carácter general y perteneciente al universo anglosajón, se crean otras nomenclaturas, con miras a expresar más objetivamente el pensamiento de cada cultura enfocada.

Se constata la producción de diversas denominaciones relativas al concepto de lo moderno, como el de modernismo retrasado, de autoría de Fredric Jameson, asociado a las nociones de capitalismo retrasado y de sociedad posindustrial; el de modernidad floja, planteado por Carlos Antônio Leite Brandão; el de pensamiento flojo, de Gianni Vattimo; Stuart Hall discurre sobre los conceptos de modernidades alternativas, modernidades retardadas y modernidades vernáculas. Otras denominaciones se refieren a modernidades periféricas, como es el caso de Beatriz Sarlo; el teórico indio plantea las modernidades libres (at large), en su libro Modernity at Large; Anthony Giddens se refiere a la modernización reflexiva; Homi Bhabha alude a la contramodernidad cultural, como sinónimo de temporalidad disyuntiva; y Zygmunt Bauman ha creado la noción de modernidad líquida. Antimodernos, contemporáneos, modernos desplazados, reiteran las distintas tentativas de redefinición que, lejos de cerrar la discusión sobre el tema, confirman su importancia y vulnerabilidad.

Los conceptos legados por las culturas hegemónicas son puestos en jaque y revisitados, teniendo en cuenta la importancia de las transformaciones políticas y culturales para el entendimiento actual del mundo globalizado. En toda lectura revisionista es necesario rever los conceptos y desconfiar de las certezas cristalizadas por los movimientos datados. No obstante, toda cautela es poca, pues lo que se postula como algo superado debe ser debidamente analizado en sus contradicciones y limitaciones temporales. Uno de los grandes desafíos de la crítica literaria y de la propia literatura es la actualidad/no actualidad de los términos, la muerte/resurrección de conceptos que se revelaban dotados de poca consistencia. Proponer, por el contrario, la repetición aleatoria de términos tal como fueron creados originalmente es ignorar la vitalidad/revisión de estos, en la medida en que se debe valorizar su historicidad y no su pretendida esencialidad. Las modificaciones históricas, culturales y políticas se extienden a la duración de los conceptos, los cuales pasan por transformaciones, lo que no significa olvidarlos, sino actualizarlos. Las contradicciones y la complejidad embutidas en los términos vanguardia, modernidad y modernismo, este último relativo no solo a la Semana de 1922, sino también a los representantes de los principios estéticos de los años de veinte y treinta, deben ser repensados y rearticulados. 
La imprecisión en cuanto a las distinciones entre modernidad y vanguardia, gesto común entre teóricos e historiadores, impide una equilibrada revisión historiográfica, lo que resulta en la indistinción entre los movimientos artísticos. La vanguardia, considerada generalmente como superada por lo moderno (afecto a la tradición y a lo nuevo), es aún poco considerada en lo que respecta al hábito de oponerse siempre al conservadurismo y a la repetición de formas gastadas. La ruptura de los valores tradicionales y la mirada atenta a la creatividad y al no-inmovilismo constituyen una de las tendencias de la prosa contemporánea en cuanto a la búsqueda, aun en el pasado, de inspiración para otras formas de ficción.

No es posible concebir una singularidad de principios que puedan caracterizar la prosa moderna, posmoderna o antimoderna, una vez que la multiplicidad de tendencias y de estilos impide la presencia de un cuadro unívoco de esas estéticas. Sin embargo, prevalecen aún las intransigencias de género, la fragmentación en demasía, la desconfianza de los medios de comunicación de masas, la apropiación de tecnologías que amplían el público-lector y reducen la obra literaria a un único soporte. La crítica a la modernización no se reduce a la industrialización desenfrenada y excluyente de las grandes metrópolis de principios del siglo XX, sino también al ritmo actual de la ruptura de los eslabones personales y sociales.

Muchas son las protestas contra la mala literatura hoy por hoy. La aceptación por parte del mercado de un texto escrito cualquiera confirma que las conquistas del modernismo en cuanto a no distinguir la alta de la baja literatura -conservando sin embargo una posición elitista frente a las manifestaciones populares- están lejos de realizarse. La inadecuación entre la élite y el pueblo, con avances que no se deben desechar, guarda preconceptos que podrán un día ser eliminados.

\section{El modernismo y sus relecturas}

\section{"A semaninha" de Belo Horizonte y las modernidades diuturnas}

Con el objetivo de dar continuidad a esta discusión sobre el modernismo y sus posibles fragmentaciones y variaciones, retomo la investigación desarrollada por un grupo de la UFMG, coordinado por Wander Melo Miranda, intitulada "Modernidades tardías". Con ese proyecto conseguimos reflexionar sobre los conceptos de lo moderno y de modernidad tardía, así como apuntar los residuos de una época y su relectura en el presente. El concepto de residuo es tributario tanto de las investigaciones de Walter Benjamin como de las de Raymond Williams, cuando este último lo define: 
[...] como algunas experiencias, significados y valores, que no pueden ser verificados o expresados en los términos de la cultura dominante, [y que] son, a pesar de todo, vividos y practicados sobre la base de un residuo -tanto cultural como social- de alguna formación social previa. (218)

La recuperación del concepto permite entender que el residuo es, por definición, formado en el pasado, pero que continúa activo en el proceso cultural, no solo como elemento del pasado, sino en cuanto tiene una efectiva actuación en el presente. La estética del fragmento y de la ruina en Benjamin reconduce también a este raciocinio, indiferente al principio de totalidad. Georg Otte así se expresa con respecto a la estética de la ruina de Benjamin:

Y ya que las ruinas del presente son testigos del pasado, por más fragmentarias que sean, esos fragmentos se vuelven importantes para ser el punto de partida en la búsqueda de esta comprensión, pues " ¿no somos tocados por un soplo del aire que fue respirado antes? ¿ ${ }_{\mathrm{i}}$ No existen, en las voces que escuchamos, ecos de voces que maduraron?" (305)

Las resonancias tardías de lo moderno pueden ser detectadas en la revolución arquitectónica operada en el Brasil a partir de la década de 1930, con la presencia del arquitecto francés Le Corbusier, auxiliado por Oscar Niemeyer, Lúcio Costa y Burle Marx. Es posible destacar el momento en que, de manera peculiar, arte y tecnología se articularon con el auspicio del Estado, en pos del proyecto de construcción del edificio del Ministerio de la Educación en Río de Janeiro y del conjunto de la Pampulha, en Belo Horizonte, en la década de 1940, durante la gestión del entonces alcalde Juscelino Kubitschek.

La educación moderna brasileña, con plena realización en las áreas de la literatura, las artes plásticas y la música, recibió un nuevo impacto y se configuró, tardíamente, en los proyectos arquitectónicos. El proyecto de la Pampulha, dibujado para instalarse en la periferia de una ciudad moderna y recién construida, dio continuidad a las obras anteriores firmadas por sus autores, además de abrir el camino para la construcción de Brasilia, ópera prima del arte concreto. Inaugurado en 1942 -a excepción de la iglesia de San Francisco-, el conjunto arquitectónico representaba, en el Brasil, el desdoblamiento que tuviera inicio, en los años veinte, en los planos literario y artístico. Con trazos racionalistas y abstractos, volcado hacia el carácter internacional que presidia su proyecto estético y la singularidad del arte de Niemeyer, el conjunto arquitectónico añadió otra dimensión al concepto de lo moderno.

Como contrapartida a la hegemonía político-cultural de los centros metropolitanos internos y externos, la conciencia de quien llega tarde en la historia del 
progreso y de lo nuevo, cuando lo moderno parece ya estar consumado, revierte la ansiedad del retraso y del débito a favor de una construcción conceptual $a$ posteriori, que sea capaz de dar cuenta, de elaborar conexiones alternativas del arte con la política, de la cultura con la vida social. En este caso, la noción de moderno retraso no debe servir solamente para pensar la constitución del Estado nacional brasileño, desde el punto de vista de Belo Horizonte y, después, desde el proyecto que culmina con la construcción de Brasilia. Más que esto, nos debe hacer ver, con la claridad necesaria, lo que allí se narra de la propia modernidad.

La construcción del conjunto arquitectónico de la Pampulha, en un área alejada del centro de la ciudad, revela la intención de desplazar los espacios legitimados por el poder estatal, al dirigirse a una región aún no explorada, una región de diversión y un lugar del futuro. Se instaura una nueva concepción de ciudad que, al lado de la joven Belo Horizonte, le añade atributos capaces de hacerla más atractiva para el ciudadano cotidiano. El área de diversión representaría la apertura no solo a nuevos espacios sino también a nuevos tiempos, por lo cual se crea un ambiente cosmopolita, con la presencia de conciertos en el casino, a cargo de artistas de varias partes de Brasil y del mundo.

En 1944, por invitación de Juscelino Kubitschek, una caravana paulista y otra carioca visitaron la ciudad, con el objetivo de conocer el moderno conjunto arquitectónico de la Pampulha. La "Exposición de arte moderno" ("a Semaninha"), con obras de los exponentes del modernismo de la década de 1920, y de otros que los siguieron, como Tarsila, Di Cavalcanti, Malfatti, Portinari, Scliar y Guignard, reforzó el deseo de unir la vanguardia artística con el paisaje urbano y los ideales políticos. Con el objetivo de romper con el conservadurismo, una de las acepciones más estereotipadas de la tradición, el concepto de lo moderno resurgió bajo el signo de la ruptura y del desarrollo industrial, a partir del ejemplo de la revolución artística operada en la literatura y en las artes de este periodo. La arquitectura de la década de 1940, tardíamente concebida como moderna, llenó el vacío del momento y se levantó como reconstrucción de lo nuevo y de la recuperación del progreso.

El invitado modernista de la fiesta que congregó los dos momentos de vanguardia artística, 1922 y 1944, no fue Mário, sino Oswald de Andrade. Representante de una posición más anarquista, tanto en la literatura como en la política, el autor de Memórias sentimentais de foão Miramar fue el curador de la exposición y por esa razón se convirtió, durante la visita, en el embajador del modernismo, al legitimar la continuidad entre pasado y presente, en la conferencia que dictara en Belo Horizonte, intitulada "El camino recorrido". La pretendida continuidad atendía al llamado político de Kubitschek, dispuesto a atar los hilos 
de la historia moderna con la lección vanguardista del pasado. Las supresiones y los desfases temporales fueron borrados en nombre de la repetición y del retorno que se configuró como continuo e igual, si el propósito servía a intereses direccionados a las redefiniciones históricas del nacionalismo y del populismo:

Me preguntó alguien si el título que di a esta conferencia, "El camino recorrido", indicaba el trayecto ferroviario de São Paulo a Belo Horizonte. No dije que no. Y me quedé pensando en esa curiosa analogía en que la distancia geográfica entre las dos capitales puede ilustrar una etapa superada en el tiempo. El camino recorrido del 22 al 44. São Paulo del Centenario, Belo Horizonte de Juscelino Kubitschek. En el 22, São Paulo empezaba. Hoy Belo Horizonte concluye. Porque mientras Minas procura unificar el Brasil, São Paulo se dispersó en setenta ollas y fue preciso venir a Belo Horizonte para dar el espectáculo de una familia solidaria y respetable. (Andrade, "O caminho percorrido" 93)

Distinta posición política asumió Mário de Andrade en la conferencia realizada en 1942 en el Itamaraty, al hacer el balance del movimiento que cumplía veinte años. La conferencia de 1942 deshizo, sin embargo, el mito del modernismo como movimiento inmune a críticas e instauró la necesidad de romper con la idea del pasado como herencia recibida a ojos cerrados. En el texto de 1942 se señalan los equívocos del movimiento, al repetir el gesto destructivo del ensayo "Mestres del pasado", cuando la poética innovadora exigía la ruptura con la poesía parnasiana. El disgusto por el momento presente -la dictadura de Vargas y la Segunda Guerra Mundial- serviría de marco para entender la diferencia entre los dos Andrades. En Oswald, el espíritu revolucionario y de vanguardia se verificaba en la resurrección del 22 por la acción igualmente revolucionaria de Kubitschek. La política aún servía de palanca para el cruce de la lucha literaria iniciada anteriormente. En Mário, la desilusión por no encontrar en el pasado ningún eslabón de ligadura con el presente generó un sentimiento de fracaso y no acreditó más los antiguos ideales.

Es todavía curioso comprobar que este viaje de los paulistas a Minas Gerais en 1944, por lo tanto veinte años después del "viaje de descubrimiento del Brasil", no solo erige el barroco como fuente de la nacionalidad brasileña moderna, sino que también enlaza el movimiento revolucionario de Tiradentes al de Kubitschek, ahora resaltando otra dimensión de las modernidades tardías. Atribuye incluso una connotación más política a la antropofagia, por su militancia comunista y la preocupación más comprometida con los ideales populares. Minas antigua nos dio las grandes lecciones de la Inconfidencia, las 
grandes lecciones de Aleijadinho. La tierra de poetas, novelistas y narradores sería, según Oswald, más propicia a la lucha por la democracia y la igualdad entre los pueblos. La sensibilidad política dependería, por tanto, de la acción de los intelectuales, del compromiso y de la solidaridad con el pueblo y la clase más desprotegida. En verdad, lo que se proponía consistía en una especie de ajuste de cuentas con la realidad social, una respuesta a la crítica de Mário y de otros al aspecto aristocrático del movimiento modernista.

La producción literaria y artística de la época contaba entre sus representantes más notables a los modernistas que aún permanecían en la ciudad, como Cyro dos Anjos, Abgar Renault y Henriqueta Lisboa, además de los nuevos que empezaban a inscribirse en el escenario intelectual del momento. Alphonsus de Guimaraens Filho, Murilo Rubião, Fernando Sabino, Autran Dourado, Hélio Pellegrino, Otto Lara Resende, entre varios otros, publicaron sus primeros textos literarios en la década de 1940, además de ejercer ya la profesión de periodistas. Algunos de estos jóvenes intelectuales serían los futuros compañeros de Kubitschek en la vida pública, aun cuando para la época su posición fuera contraria a la política municipal, vista por ellos como sucesora de la dictadura de Vargas.

Belmiro Borba, personaje de $O$ amanuense Belmiro, de Cyro dos Anjos, publicada en 1937, tiene como escenario Belo Horizonte, ciudad republicana y moderna, en donde se condensa el pasaje de lo antiguo con lo nuevo, del interior con la capital, del ambiente rural del campo con la modernización urbana. La modernidad cultural llega por los libros extranjeros ávidamente adquiridos en la calle Bahía, razón por la cual es posible entender la atmosfera de lo nuevo que inspiró la intelectualidad de Minas Gerais, que residía en una metrópoli nueva y moderna. El desarraigo del sujeto, la pérdida de la individualidad en medio de la multitud y la separación entre la esfera privada y la pública -responsable de la legitimación del ejercicio de la democracia, uno de los lemas de la política moderna, instauradora de los patrones republicanos- redimensionan la vida en sociedad y componen el escenario del libro. Sin embargo, surge la pregunta: $\dot{C}^{\mathrm{a}}$ cuál modernidad pertenece la escena montada por el amanuense Belmiro?

Su obra se justifica por la concordancia con la poética contemporánea, justamente por no circunscribirse al modelo modernista y desvincularse de la propuesta nacionalista que marcó la mayor parte de la producción de los años veinte y treinta. En el penúltimo capítulo de $O$ amanuense Belmiro, "Mundo, mundo", la descripción del sueño del personaje evoca la escena modernista, compuesta por Carlos Drummond, Emílio Moura y un poeta sin nombre. Clasificando a los dos primeros respectivamente como poeta irónico y místico, y al sin nombre como intérprete de la poesía popular y anónima, el amanuense 
presta el debido nombre a sus amigos, y así registra las dos vertientes de la poesía modernista, aliada de la tercera, la popular. Sin elegir cuál camino seguir, la escena-sueño se cierra con la imagen festiva de un congraciamiento de todos: "Después, brazos dados dando vueltas alrededor de mí y acompañados por el jefe de tren, que soplaba un gran trombón, cantaban una voce: 'Mundo mundo vasto mundo / más vasto es mi corazón"' (Anjos, O amanuense 227).

La posición de Cyro dos Anjos entre los modernistas es afirmada, de modo directo, en $A$ menina do sobrado, cuando comenta su experiencia en el periódico $O$ Diário, al lado de Carlos Drummond, Emílio Moura y João Alphonsus:

Se oficializó, de este modo, la adhesión, medio cómica, del compañero que entraba en el fuego cuando algunos ya habían salido de él, que, a final de cuentas, ningún fervor llevaba en el alma. Mi actitud genuina, delante de modernistas y pasadistas, se asemeja a la del viejo Horácio, hijo de Bernardo Guimarães y primo del João, a quien igualmente conocí en el Diário, como redactor de tópicos: cético, resistente a radicalismos, Horácio veía a los mozos con ojos sonrientes, llenos de simpatía, derramando comprensión, pero ni por esto echaba a los viejos a la guerra; menos, tal vez, por apego a su generación que por fidelidad a su musa, a duda. En verdad, yo no me comprometía en aquel movimiento pronto a desintegrarse. (Anjos, A menina 395)

El ensayo de Carlos Antônio Leite Brandão "La 'modernidad floja' de las 'esquinas' de Belo Horizonte y Cyro dos Anjos" tiene el mérito de esclarecer la relación entre esta modernidad que él denomina flaca y la tardía, pues el autor entiende que, con respecto al modernismo del 22, el nuestro fue flaco, frágil y retrasado. El ejemplo utilizado para expresar este argumento es el del lenguaje de la arquitectura art déco de los años treinta en Belo Horizonte, caracterizada por un tipo de lo moderno que presentaba un "freno al pasado, propio del hibridismo de las Minas del oro, de la tierra y del hierro" (86). La ciudad se configuraba como palimpsesto, en el cual los aspectos arcaicos transitaban hacia el futuro y experimentaban varias temporalidades y tendencias:

Por esto, decimos que nuestro modernismo fue flaco, frágil, retrasado, lo que no es necesariamente ruin, toda vez que esto nos da más plasticidad, maleabilidad y conciencia crítica sobre el propio presente, que avanza hacia el futuro al mismo tiempo que hacia el pasado. Y Belmiro, al contrario del hombre fuerte, es el ejemplo del habitante de esa modernidad en neblinas, siempre necesitada de evadirse a otras regiones del tiempo, "un hombre vacilante, un hombre sin dirección". (Brandão 103) 
Lo que se postula, en este pensamiento flaco y, como consecuencia, en esa acepción de una modernidad flaca es la ausencia del pensamiento totalizador, verdadero y fundacional, vinculado al aspecto hegemónico de las caracterizaciones artísticas y literarias. Estructuras estables y sedimentadas por el pensamiento considerado fuerte no entran en esa proposición posmoderna defendida por Gianni Vattimo.

Autran Dourado y Murilo Rubião, dos escritores que inician su carrera en los años cuarenta, asumen una estética no-figurativa en la construcción de su prosa, en la que se encuentran diluidas las marcas de referencia al espacio urbano, propias de la estética modernista. Se acentúan los trazos intimistas de los personajes al lado del aspecto abstracto del paisaje de las ciudades que ellos retratan. El cuento "O edifício", de Rubião, se desarrolla en torno de la construcción de un edificio interminable. Mediante movimientos sin interrupciones, se apropia del rascacielos como motivo irónico, dado que este se constituía como uno de los íconos de la ciudad y de la literatura moderna. El desarreglo entre el carácter progresista y eufórico de la modernización urbana operada en esta época en Belo Horizonte y el texto de Rubião refuerza la necesidad de que se lean por el reverso, y según una perspectiva crítica, las contradicciones existentes entre los dominios del arte, la política y los desvíos de la modernización.

No es sin razón que Mário de Andrade, en sus muchas cartas intercambiadas con los de Minas Gerais, extraña los nuevos estilos en la prosa, marcados por la abstracción, por la ausencia de una propuesta nacionalista y a favor de la deconstrucción del paisaje urbano. La inmersión en la vida del interior y en la falencia de la sociedad patriarcal motivaba la producción de una narrativa que se desvinculara de la ambición modernizadora de los modernistas y se concentrara en la figuración de un país rural e íntimo. Lúcio Cardoso, Clarice Lispector, Murilo Rubião, Autran Dourado, entre otros, disonaban en el proyecto planeado por el grupo modernista, aunque conservaran lo más rentable y permanente que fuera dejado como herencia: la defensa de un lenguaje limpio, sin retórica y próximo a lo cotidiano y al hombre común.

No obstante, la respuesta literaria proporcionada por los escritores no se filiaba a la estética modernista hegemónica, no solo porque estaba exhausta, sino por cambios en la fisionomía de la ciudad y por su posición estética diferente frente a la propia idea figurativa urbana. Se desviaba también de la propuesta política de Kubitschek, pautada por el desarrollismo y por el progreso como salidas hacia una modernización urbana y triunfante. 


\section{El ensayismo de Silviano Santiago}

Mi participación como lectora del modernismo, y principalmente del lugar de Mário de Andrade en esta fase de la literatura brasileña, comenzó después de la publicación de mi tesis de doctorado "Macunaíma, a pedra mágica do discurso". En realidad, cuando comencé a estudiar y publicar la correspondencia de Andrade con los escritores de Minas Gerais -Henriqueta Lisboa, Murilo Rubião, entre otros- fue posible ampliar el enfoque no solo literario sino también biográfico y cultural. A partir de esta lectura, el lugar del escritor podía ser releído con base en criterios que respondían a su caracterización ambigua y paradojal. Sobre este particular, se hizo necesario remitir al trabajo pionero de Silviano Santiago, que en la década de 1980, en la Pontifícia Universidade Católica do Rio de Janeiro (PUC/Río), fue el responsable de la apertura de los estudios sobre correspondencia, específicamente en el modernismo, con el objetivo de hacer el mapa y revelar el papel del intercambio de cartas para la consolidación del movimiento, así como de apuntar los equívocos y resquicios de una modernidad en movimiento. Es también pertinente mencionar las investigaciones desarrolladas en Río de Janeiro por Renato C. Gomes, Beatriz Resende, Flora Süsekind, Marília Cardoso, entre otros ${ }^{3}$, referentes a la elección de autores considerados por el canon modernista como premodernos, como João do Rio, Lima Barreto, Euclides da Cunha, Benjamin Costallat, Murilo Mendes, Lúcio Cardoso y Cornélio Pena. Estos investigadores consiguieron romper con el enfoque de las investigaciones realizadas en la Universidade de São Paulo (USP), que se centraban en la consolidación del modernismo. La propuesta resultó en el análisis sin retoques y afeites del movimiento y de la obra de sus autores, al contrario de lo que se estaba haciendo en otros centros de investigación, volcados hacia la reformulación no canónica de la historiografía literaria.

La posición de Silviano Santiago frente a la estética modernista brasileña se caracteriza por una lectura por intervalos, perspectiva analítica direccionada al balance del movimiento de modo que respete lo que aún posee de fructífero para la comprensión del momento presente o lo que solo se sustenta en términos literarios y teóricos. Sin acudir a criterios binarios, pautados por la exclusión de términos en favor de otros, el ensayista señala, en un artículo referente a las conmemoraciones de los sesenta años del modernismo, la necesidad de realizar el balance del movimiento de forma que no solo se legitimen sus conquistas, sino que también se señalen sus equívocos, se cierre el círculo y se corte el cordón umbilical con el pasado.

Véanse las publicaciones de historiadoras como Velloso y Gomes. 
La cuestión es la siguiente: ¿de qué manera la estética de la novela modernista genera hoy, para el joven escritor brasileño, trampas artísticas e ideológicas de las que él debe liberarse, para que corte de una vez por todas el cordón umbilical que aún lo ata a estos "maestros del pasado", para usar la gloriosa expresión de Mário de Andrade en contexto pasado y semejante? Pensamos así porque el proyecto básico del modernismo -que era la actualización de nuestro arte mediante una escritura de vanguardia y la modernización de nuestra sociedad por medio de un gobierno revolucionario y autoritario- ya fue ejecutado, aunque discordemos con la manera como la modernización fue implantada entre nosotros. (Santiago, "Fechado" 76).

Lo que sustenta esta evaluación es la perspectiva del presente, estrategia capaz de entender el pasado por medio de la lógica del suplemento de Jacques Derrida, es decir, el "añadir algo a lo que ya es un todo". No se trata de considerar el texto anterior como incompleto e intentar completarlo, ejercicio por demás repetitivo y parasitario, sino de partir de situaciones consolidadas a fin de generar formas transgresoras. En este sentido, los personajes que componen el cuadro del modernismo brasileño -Mário y Oswald de Andrade, Murilo Mendes, Jorge de Lima, Carlos Drummond de Andrade, entre otros- no se presentan para el ensayista de modo intocable e instalado tranquilamente en este canon. Reciben tratamiento crítico sin la adopción de un pensamiento binario, de principios excluyentes: son interpretados según la lógica del diálogo, del contraste y de la paradoja. Se procede al descentramiento de la estética modernista, confrontada con la de los autores premodernistas, como Euclides da Cunha o Lima Barreto, cuya obra rompe con los principios modernizadores y los ideales de progreso. Rever lo que fue reprimido por la crítica o lo que sufrió el proceso de exclusión a fuerza de criterios de universalización del canon oficial es una de las propuestas añadidas a la lectura deconstructora del modernismo realizada por Santiago: "¿qué se puede aprender en los textos de Lima Barreto y Euclides da Cunha, que dejan afuera los patrones estéticos e ideológicos establecidos por la estética modernista?" ( "Fechado" 88).

Es incisivo el llamado del crítico a la revisión de los modelos modernistas, teniendo en mente las transformaciones de orden político y cultural causadas por eventos mundiales, además de la lucha por los derechos de ciudadanía de las minorías y organismos afines. En este sentido, los paradigmas de la modernidad han sido revisitados por la crítica contemporánea, con el objetivo de extender el horizonte interpretativo, sin restringirse solo a la aproximación literaria, sino también imponiéndose como crítica cultural. Reside allí una de las mayores 
reacciones al aprisionamiento teórico a las que se somete gran parte de la crítica. En un artículo de 1995, "Atracción del mundo", Santiago señala el impasse de las culturas periféricas frente al entonces naciente proceso de globalización y alerta del cambio de posicionamiento crítico y teórico, y de la revisión de los conceptos frente a las transformaciones sufridas por la "rápida globalización del capitalismo periférico" ("Atração do mundo" 38).

La deconstrucción de los principios universalistas erigidos por la civilización europea, con fuerte impacto en los estudios contemporáneos, es vista por el ensayista como legado del modernismo, pues, aunque se pensara en la consolidación de una nacionalidad artística, Mário y Oswald de Andrade lucharon por el reconocimiento de la civilización indígena y por la apertura a otras civilizaciones. En la percepción de América Latina como una cultura híbrida, exenta de radicalismos relativos a los sentidos de pureza y unidad, y por esa razón capaz de transgredir modelos e inventar respuestas propias, Santiago remite a la lección de Oswald sobre el tema, al considerarlo como uno de sus precursores teóricos en el artículo "O entre-lugar do discurso latino-americano". El argumento encontrado es la mixtura de razas, la "mulatización", que, comparado con las nuevas formas del multiculturalismo, no se vincularía a la posición defendida por Gilberto Freyre:

La Alemania racista, purista y recordista necesita ser educada por nuestro mulato, por el chino, por el indio más retrasado del Perú y de México, por el africano de Sudán. Y necesita ser mixturada de una vez para siempre. Necesita ser deshecha en el melting-pot del futuro. Necesita mulatizarse. (Andrade, Ponta de lança 18)

Mário de Andrade provee igualmente ingredientes al sustento del pensamiento multicultural contemporáneo, al ser citado en un ensayo dedicado a la tolerancia racial en Oswald de Andrade. En este texto recalca la lucidez del escritor paulista que, en 1924, aunque defendiera el nacionalismo como primera preocupación, se abría a la comprensión de la existencia de varias etnias. El empleo del plural para el término civilización sirve como apertura a la multiplicidad cultural y funciona como previsión para el debate actual del tema: "Los tupis en sus tabas eran más civilizados que nosotros en nuestras casas de Belo Horizonte y S. Paulo. Por una simple razón: no hay Civilización. Hay civilizaciones" (Andrade, O., ctd. en Santiago, "O entre-lugar" 18).

El ensayo "A permanência do discurso da tradição no modernismo" (Santiago 2002) representa, en la crítica brasileña, una de las reflexiones más agudas sobre la poética modernista, a la luz de una lectura posmoderna. Considera que 
en la tradición de la propia crítica fue prioritario el endoso de la estética de la ruptura, responsable de la exclusión de varios escritores que no seguían esos parámetros, como Murilo Mendes, o los textos filosóficos de Oswald de Andrade. La defensa de poéticas vanguardistas por la crítica y por los escritores-críticos motivó la restricción de patrones estéticos, la elección de determinados nombres para componer el canon modernista, además del desprecio por la producción que no fuera literaria, como la correspondencia, las memorias, los ensayos y otros textos. La apertura al enfoque de talante cultural y político, al colocar entre paréntesis la valorización de lo estético en sí y del inmanentismo textual, es motivada, en la obra de Santiago, por el ejercicio de la crítica memorialista y por la atención dirigida a la correspondencia de Mário de Andrade, así como por la atención dedicada a la cultura de masas. Si en la década de 1970 una parcela de la crítica aún se inclinaba por el endoso de las estéticas de la ruptura, teniendo la poética oswaldiana como emblema, en la década de 1980 la obra de Mário y su papel como intelectual fueron reconsiderados de forma pionera por Santiago.

Pero el cambio que ocurrió en la crítica académica en la década de 1980, principalmente relacionada con la preferencia por los autores modernistas, recibió del ensayista un autoanálisis, pues este incorporó, en los años setenta, la vertiente elitista del arte de la cual Oswald de Andrade fue uno de sus exponentes (y que Mário ya había denunciado en la conferencia de 1942). En "O teorema de Walnice e a sua recíproca" (1981) vuelve a prender el debate sobre la compleja relación entre escritor y Estado, y entre obra literaria y público lector, con el objetivo de, entre otras consideraciones, discutir sobre el arte y el mercado. La conocida frase de Oswald de Andrade, "la masa aun comerá la galleta fina que fabrico", es uno de los argumentos reveladores de la actitud jerarquizante de este escritor y del modernismo en cuanto al diálogo entre la obra y lo público. Es elitista por desplazar la atención hacia el público, con la confianza de que algún día este podrá comer la galleta fina, alcanzando el valor y la cualidad de la verdadera obra de arte. En este sentido, Santiago se distancia de la premisa de Oswald, al acreditar que el pensamiento del modernista se definiría por la "estetización de lo popular", cuya función sería la de conservar el saber erudito. No deja tampoco de reconocer que en el año de 1972, con ocasión del cincuentenario de la Semana de Arte Moderno, "se reinstala el proyecto modernista" y "se redefine el arte brasileño como arte elitista", lo que atravesará toda la década ${ }^{4}$.

4 "O Oswald de Andrade, que eu costumo citar com alguma frequência, é o ópio: 'a massa ainda comerá o biscoito fino que eu fabrico'; em outras palavras, acredito mais na educação do que no saber da massa. Quer dizer, esse saber da massa não pode ser trabalhado pela cultura, ele não pode consumir a cultura que eu fabrico, porém, se houver educação, se esse pessoal 
Las aproximaciones entre Santiago y Oswald de Andrade se verifican en el ámbito literario, al ser incorporada la poética oswaldiana en varias obras. Los cuentos de $O$ banquete (1970), de temática antropofágica, se inclinan hacia la revitalización de la parodia oswaldiana y hacia la exploración de ingredientes de la cultura pop y tropicalista. El libro de poemas de 1978, Crescendo durante a guerra numa província ultra-marinha, se apropia de esa poética mediante la utilización de collages textuales, de ready-made lingüísticos, de la indistinción entre prosa y poesía, en una clara alusión a la herencia del modernista y al momento político de la década de 1940. La referencia a ese periodo contiene tanto el relato de las experiencias familiares del joven que crecía durante la guerra como en el momento presente, para mencionar la dictadura militar brasileña. En esa misma línea de creación-apropiación de textos ajenos, reescribe la crónica de Mário sobre el viaje de la caravana paulista a Minas, valiéndose, antropofágicamente, de la dicción oswaldiana, pero empleando el pastiche como recurso poético.

En ese poema titulado "O dentro do dentro do dentro", por medio del montaje de citaciones, Santiago reverencia al mismo tiempo a Oswald y a Mário, transgrediendo, de forma lúdica y alegre, los textos originales. Como suplemento al viaje modernista, Santiago resalta lo que sobra de esa poética, superando la propuesta, sin pensar en completarla. El trabajo de restauración del texto-modelo juega con el sentido de incompletitud y de exposición de las varias voces allí inscritas. Se disfraza de ejercicio poético que dialoga con el ensayo "La permanencia del discurso de la tradición en el modernismo", en el sentido de hacer presentes los ecos y ruinas de lo moderno y traerlos a la superficie de la escritura contemporánea. Relee, de esa forma, la propuesta oswaldiana, al apropiarse de la crónica de Mário sobre el viaje a Minas en 1924, transformando la prosa en poesía y siguiendo el procedimiento de ready made utilizado en el libro de Oswald, Roteiro de Minas, de 1925.

Si en el artículo "Cerrado por inventario" Silviano registra el año de 1936 como la proclamación de la muerte del modernismo del 22 encarnada en la crítica hecha por los colaboradores de la revista Lanterna Verde, la fecha remite tanto al nacimiento del escritor como al encarcelamiento de Graciliano a manos de la represión del gobierno de Vargas. La utilización del artificio autobiográfico cumple una función metafórica, al aproximar referencias documentales que contestan, tanto por la ambigüedad y transfiguración de lo ficcional como por la contextualización

for preparado, eles vão consumir. [...] É, deslocam o Mário porque ele inegavelmente tem mais abertura para o saber popular. E Oswald de Andrade não tem essa abertura; ele tem abertura para uma estetização do popular, mas não para o saber popular" (Santiago, "Um intelectual entre a vanguarda" 213). 
de la escritura de Santiago como intelectual. Se procede a la doble relectura del modernismo, ya sea a través de la figura de Graciliano, ya a través de En liberdad, una de las primeras manifestaciones de la literatura posmoderna entre nosotros.

\section{Obras citadas}

Andrade, Oswald de. "O caminho percorrido". Ponta de lança. Obras completas. Río de Janeiro: Civilização Brasileira, 1972. 5-16.

— "Sol da meia noite". Ponta de lança. Río de Janeiro: Civilização Brasileira, 1972. 63-64.

Anjos, Cyro dos. A menina do sobrado. Belo Horizonte: Garnier, 1994 .

-O amanuense Belmiro. Belo Horizonte: Garnier, 1994.

Benjamin, Walter. Obras escolhidas. Vol. 1: Magia e técnica, arte e política. São Paulo: Brasiliense, 1985 .

Brandão, Carlos Antonio Leite. "A 'modernidade fraca' das 'esquinas' de Belo Horizonte e Cyro dos Anjos". Modernidades alternativas na América Latina. Eds. R. Marques y E. M. Belo Horizonte: Universidade Federal de Minas Gerais (UFMG), 2009. 100-116.

Capela, Carlos Eduardo S. Fuó Bananére, irrisor, irrisório. São Paulo: Nankin; Edusp, 2009.

Gomes, Ângela de Castro. Essa gente do Rio... modernismo e nacionalismo. Río de Janeiro: Fundação Getúlio Vargas, 1999.

Otte, Georg. "A preciosidade dos farrapos. A transvaloração dos valores em Walter Benjamin". Crítica e coleção. Eds. W. M. Miranda y E. M. Souza. Belo Horizonte: Editora UFMG, 2011. 289-307.

Santiago, Silviano. Crescendo durante a guerra numa província ultra-marinha. Río de Janeiro: Francisco Alves, 1978.

— "O entre-lugar do discurso latino-americano". Uma literatura nos trópicos. São Paulo: Perspectiva, 1978. 11-28.

- "O teorema de Walnice e sua recíproca". Vale quanto pesa: ensaios sobre questões político-culturais. Río de Janeiro: Paz e Terra, 1982. 69-88.

— "Atração do mundo". O cosmopolitismo do pobre. São Paulo: Companhia das Letras, 1989. 192-193.

— "Fechado para balanço". Nas malhas da letra. São Paulo: Companhia das Letras, 1989. 75-93.

— "O dentro do dentro do dentro". Nas malhas da letra. São Paulo: Companhia das Letras, 1989. 107-133.

— "Oswald de Andrade ou: elogio da tolerância étnica". Anais do 2. Congresso Abralic. Vol. 1. Belo Horizonte: Faculdade de Letras, 1991. 79-91. 
- "A permanência do discurso da tradição no modernismo". Nas malhas da letra. Río de Janeiro: Rocco, 2002. 108-144.

— "Um intelectual entre a vanguarda e o consumo. Entrevista concedida aos pesquisadores do Núcleo de Estudos Musicais do Centro de Estudos Sociais Aplicados da Universidade Candido Mendes e professores do Departamento de Sociologia da PUC-Rio". Cadernos do Departamento de Filosofia da PUC-Rio 16 nov. 2003). 67-79.

Senna, Homero. República das letras: entrevistas com 20 grandes escritores brasileiros. Río de Janeiro: Civilização Brasileira, 1996.

Williams, Raymond. "Base e superestrutura na teoria cultural marxista". Revista USP 65 (mar.-may. 2005). 209-224.

Velloso, Mônica Pimenta. Modernismo no Rio de faneiro. Río de Janeiro: Fundação Getúlio Vargas, 1996. 